Volume $3 \cdot$ Nomor $3 \cdot$ Juni 2020

Pege (Hal.) : $17-29$

(C) Universitas Pamulang

JL.Surya Kencana No.1 Pamulang, Tangerang Selatan - Banten

Telp. (021) 7412566, Fax (021) 7412491

website. : Email : jurnalmarketing.unpam@gmail.com

\title{
Respon Konsumen terhadap Image Appeal Iklan Media Sosial: Studi pada Follower Instagram UKM Rendang
}

\author{
Irwan ${ }^{1}$; Dessy Kurnia Sari²; Danny Hidayat ${ }^{3}$; Donard Games ${ }^{4}$; \\ Hutria Yosmarisa ${ }^{5}$ \\ ${ }^{12345}$ Universitas Andalas, Kampus Unand Limau Manih, Padang, 25163, Sumatera Barat, Indonesia \\ *Email korespondensi: dessyks@eb.unand.ac.id
}

\begin{abstract}
Abstrak. Studi ini bertujuan untuk mempelajari pendapat konsumen terkait dengan iklan di media sosial yang menampilkan gambar dan video. Lebih lanjut, pada studi ini juga dipelajari pandangan follower Instagram sebuah UKM di Sumatera Barat terhadap image appeal yang ditampilkan pada iklan media sosial. Penelitian ini melakukan suatu konten analisis untuk melihat respon dari ribuan konsumen yang merupakan Follower dari Instagram Rendang Gadih, Payakumbuh, Sumatera Barat, untuk mengetahui kategori iklan media sosial dengan respon dan interaksi terbanyak. Selanjutnya, secara kuantitatif, dilakukan survey pada 100 orang Follower Instagram Rendang Gadih. Temuan memperlihatkan bahwa pada Instagram Rendang Gadih Payakumbuh, konsumen menilai gambar yang baik adalah ketika gambar dan video memperlihatkan tampilan produk baik dalam bentuk kemasan maupun saran penyajian yang ditampilkan oleh food vlogger. Video dengan tayangan terbanyak adalah video dengan menampilkan artis ternama Indonesia. Pilihan gambar dan video yang tepat ini membuat konsumen tidak bosan terhadap tampilan sebuah akun media sosial. Dengan Image Appeal yang tepat, konsumen akan merasa ingin terlibat dalam interaksi pada media sosial.
\end{abstract}

Kata Kunci: Image Appeal, Usaha Kecil Menengah, Social Commerce, Iklan Media Sosial

Abstract. This study aims to learn about online consumers, including their responses related to advertising on social media. In detail, this study sees how the views of Instagram followers of an SME in Payakumbuh, West Sumatra, Indonesia, in terms of social media advertising. This study conducted a content analysis to analyse responses from thousands of Followers on Instagram of Rendang Gadih, Payakumbuh, West Sumatra. This study also finds out the category of SMEs' social media ads with the most interactions and responses. Then, quantitatively, a survey of 100 Instagram followers of Rendang Gadih was also conducted. The findings show that consumers gave a high appreciation on social media ads when the pictures and videos on the ads show a nice packaging and a real product with a clear explanation related to the product. In this study, the video with the most views is a video featuring famous Indonesian artists. The right choices of images and videos make consumers do not feel bored with the appearance of a social media account. With the right Image Appeal, consumers will feel like being involved in interactions on social media as expected by online marketers.

Keywords: Image Appeal; Small Medium Enterprises; Social Commerce; Social Media Advertising 


\section{A. PENDAHULUAN}

Berbagai daerah di Indonesia terkenal dengan kuliner yang lezat yang mendunia, salah satunya Sumatera Barat. Salah satu makanan khas Sumatera Barat, dengan etnik Minangkabau adalah rendang. Menurut Nurmufida, Wangrimen, Reinalta, dan Leonardi (2017) istilah "rendang" berasal dari kata "marandang" yang bermakna "secara lambat". Makna marandang merujuk pada lamanya waktu memasak rendang untuk mengahasikan tekstur daging yang empuk dan rasa yang enak dengan warna rendang cokelat gelap menandakan kadar air yang ada dalam rendang tersebut sudah berkurang. Masyarakat Minang memiliki kepercayaan bahwa rendang memiliki 3 makna tersirat yaitu makna tentang kesabaran, kebijaksanaan dan kekuatan. Ketiga makna ini dibutuhkan dalam proses memasak rendang, hingga terciptalah rendang yang memiliki cita rasa tinggi. Maka tak heran jika konsumen yang menyukai makanan ini makin tersebar tak hanya di Indonesia namun juga di mancanegara.

Usaha Kecil dan Menengah atau yang lazim dikenal dengan UKM pun makin banyak yang melirik bisnis rendang asal Sumatera Barat. Salah satu UKM yang cukup kreatif dalam memasarkan produk mereka adalah UKM Rendang Gadih asal kota Payakumbuh, Sumatera Barat. Pada tanggal 10 Desember 2017 UKM Rendang Gadih asal Kota Payakumbuh Sumatera Barat menerima penghargaan UKM Pangan Award 2017 yang diserahkan langsung oleh Menteri Perdagangan Indonesia di Jakarta. Perkembangan teknologi ini, mendukung UKM untuk memasarkan dan memprommosikan produk atau jasa mereka sehingga mampu meningkatkan penjualan produk mereka. Randang produksi Rendang Gadih sudah dipasarkan ke beberapa daerah di Sumatera Barat dan provinsi lain. Rendang Gadih memiliki akun official Instagram yaitu @rendanggadih.official yang mulai bergabung pada 31 Maret 2018. Rendang Gadih mempromosikan produk dengan mengiklankan foto,video dan review dari influencer. Dalam salah satu postingan terdapat review bapak Wilian Wongso yang merupakan pakar kuliner di Indonesia, dan Irfan Hakim yang merupakan artis papan atas Indonesia. Selain memposting review, Rendang Gadih juga bekerjasama dengan foodvloger dalam mempromosikan produk. Rendang Gadih juga menggunakan fasilitas promosi yang ditawarkan oleh Instagram yaitu dengan iklan foto dan iklan Vidio. Iklan foto dan iklan video biasanya akan muncul pada time line dan instastory konsumen.

Perkembangan penggunaan media sosial di Indonesia sangat pesat. Menurut Datareportal.com (2019) menunjukan tingkat penggunaan internet di Indonesia sebesar 150 juta jiwa naik sebesar $15 \%$ atau naik 27 juta jiwa dari tahun 2018. Selanjutnya tinggat penggunaan media sosial aktif di Indonesia sebesar 130 juta jiwa naik 8,3\% atau 10 juta jiwa dari tahun 2018. Dalam mengakses media sosial, pengguna di Indonesia menghabiskan waktu yang bervariasi, rata-rata setiap hari penggunaan melalui berbagai perangkat elektronik mampu menghabiskan 3 jam 26 menit setiap pengguna media sosial. Selanjutnya menurut ICT Watch, pengguna ponsel di Indonesia mencapai 180 juta orang dari sekitar 220 juta penduduk Indonesia. Penggunaan platforms media sosial yang paling aktif di Indonesia menurut (Datareportal.com, 2019) dapat dilihat pada gambar 1 berikut ini. 
ISSN NO. (PRINT) 2598-0823, (ONLINE) 2598-2893

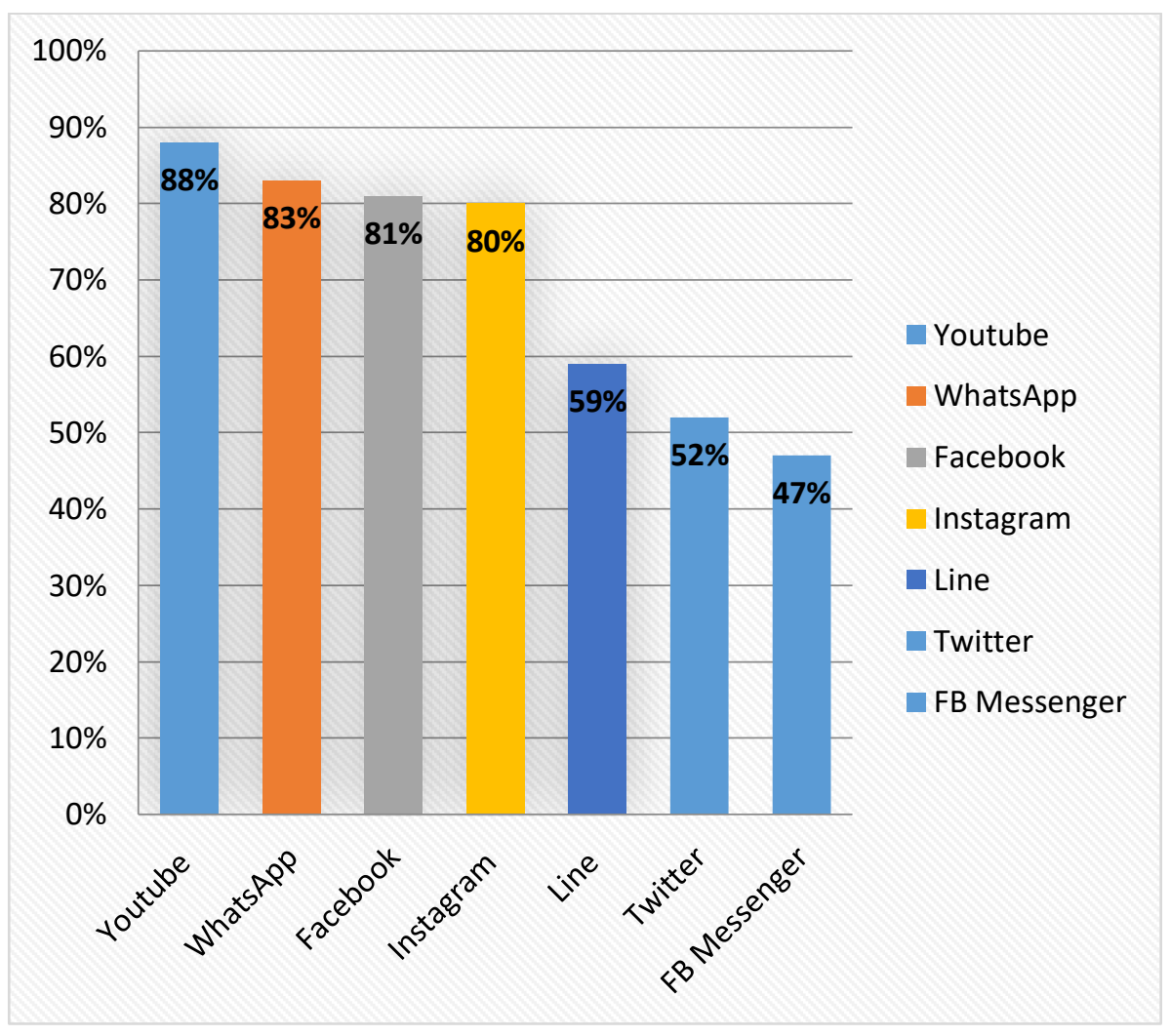

Sumber: Datareportal.com, 2019

Gambar 1 Frekuensi Penggunaan Media Sosial di Indonesia

Seiring dengan perkembangan zaman, ada tuntutan bagi UKM untuk mampu mendesain iklan yang sesuai dengan selera pasar. Dengan demikian, studi ini bertujuan untuk mempelajari pendapat konsumen terkait dengan iklan di media sosial yang telah berusaha interaktif dengan menampilkan gambar dan video. Dari aspek konsumen akan dipelajari bagaimana pandangan mereka terhadap image appeal yang ditampilkan. Apakah ada tampilan yang paling membuat konsumen menjadi tertarik berinteraksi di media sosial tersebut sehingga mengundang mereka untuk menilai iklan tersebut menjadi bermanfaat.

\section{B. KAJIAN LITERATUR}

\section{Social Commerce}

Social Commerce merupakan sebuah konsep yang saat ini tengah mendapat perhatian dari banyak perusahaan. Secara defenisi, social commerce merupakan serangkaian proses pemasaran yang dipengaruhi oleh jaringan sosial yang dimiliki oleh seorang individu konsumen yang didapatkan melalui aplikasi media sosial (Yadav, Valck, Hennig-thurau, Hoffman, \& Spann, 2013). Saat ini social commerce merupakan bagian yang penting dari e-commerce karena makin meningkatnya pengguna media media sosial. 
Hal ini menjadikan media sosial sanggap sebagai sebuah media untuk kegiatan pemasaran secara elektronik (Dong \& Wang, 2018; Han, Xu, \& Chen, 2018). Media sosial bukanlah media yang bersifat statis. Dalam media sosial muncul interaksi sosial antara pengguna dan penyaji informasi. Tak hanya itu, pada media sosial, pemasar akan saling berhubungan satu sama lain dan memudahkan untuk saling berbagi informasi satu sama lain (Han et al., 2018). Diskusi tentang harga dan kualitas produk termasuk diantara pertimbangan yang sangat berpengaruh dalam keputusan pembelian konsumen (Arianto \& Giovanni, 2020). Lebih jauh lagi, media sosial menyediakan sarana di mana pengguna media sosial agar dapat terhubung dan berinteraksi satu sama lain dengan menggunakan fitur yang disediakan oleh media sosial tersebut. Fitur media sosial mencakup chatting box, like/share, follow buttons, reviews and comment box, social recommendation systems, fungsi dari fitur yang ditawarkan oleh media sosial tersebut mampu mendukung terjadinya Social Commerce (Gonçalves Curty \& Zhang, 2013).

Kegiatan pemasaran adalah aspek kunci lain dari social commerce. Beberapa aplikasi media sosial yang awalnya merupakan aplikasi untuk berinteraksi dengan teman seperti Facebook, Intagram, Youtube pada saat ini dimanfaatkan oleh pemasar untuk memasarkan produk. Dalam skala yang lebih luas, dapat terlihat bahwa aktivitas sosial di media ini (pengalaman belanja online, komunikasi dan interaksi antar pengguna media sosial) dapat sangat menunjang aktivitas pemasaran sebuah produk. Kemudahan dalam mengakses media sosial saat ini mampu memberikan kemudahan bagi para pemasar, sehingga social commerce akan berjalan lebih efektif. Social commerce memiliki potensi lebih besar dalam meningkatkan koneksi antar pengguna secara individu dalam satu platform (Wang et al., 2019).

Social media marketing, merupakan bagian penting dalam proses komunikasi social commerce yang berfokus pada tahap pengenalan kebutuhan, pra-pembelian, dan pascapembelian (Zhang \& Benyoucef, 2016). Dengan kata lain, social commerce adalah konsep yang luas, termasuk proses kegiatan komersial yang difasilitasi oleh media sosial. Social media marketing dalam arti sempit, yang hanya berfokus pada proses pemasaran dalam social commerce. Social media marketing mencakup ulasan, peringkat, dan komentar dari interaksi komunitas pada media sosial sehingga pemasar dapat memahami kebutuhan pengguna media sosial dan meningkatkan penjualan produk (Wang et al., 2019).

\section{Stimulus Organism Response (S-O-R)}

Stimulus-Organism-Response (SOR) merupakan teori yang menyatakan pandangan yang lebih terstruktur dari faktor faktor yang mempengaruhi konsumen untuk memposting ulang produk yang mereka beli di media sosial pribadi konsumen. Pada teori SOR ini digambarkan bahwa konsumen akan memberikan respon terhadap stimulus yang didapatkannya, termasuk di media sosial. Teori ini menyimpulkan bahwa aspek lingkungan (bertindak sebagai stimulus), menyebabkan perubahan pada proses kognitif individu (bertindak sebagai organisme), yang mampu memengaruhi pola perilaku individu (bertindak sebagai respons) pada stimulus tesebut Dalam hal media sosial, konsumen yang terekspos oleh beragam gambar, video, dan informasi pada akan memberikan respon terhadap rangsangan tersebut. Seorang konsumen dapat menilai dan merespons stimulus secara positif dan efektif yang akan mengarah kepada perilaku dan keputusan pembelian mereka (Wang et al., 2019). 


\section{Perceived Utilitarian Value (Presepsi Nilai Utilitarian)}

Konsumen memiliki suatu penilaian terhadap setiap iklan yang dilihatnya termasuk di media sosial. Perceived Utilitarian Value adalah nilai yang dirasakan konsumen ditandai dengan evaluasi secara umum apakah suatu rangsangan dapat dianggap memiliki unsur manfaat (Kesari \& Atulkar, 2016; Wang et al., 2019). Dalam konteks pemasaran media sosial, pengguna media sosial termotivasi untuk memposting ulang iklan untuk memenuhi berbagai kebutuhan informasi, misalnya, menunjukkan dukungan untuk produk atau layanan, terlibat dalam diskusi, atau menerima insentif (Wang et al., 2019).

Menurut Ham, Lee, Kim, dan Koo (2019) empat pola perceived utilitarian value berdasarkan online reviews:

1 Administrative Reader

Administrative Reader atau pembaca administratif cenderung konservatif ketika menilai keaktifan peninjau serta kecukupan atau keaslian tinjauan. Mereka juga menilai keaslian ulasan berdasarkan data yang terukur atau objektif. Oleh karena itu, utilitarian value yang dirasakan dari iklan secara online dapat ditingkatkan dengan memberikan komentar baik yang ditulis oleh konsumen yang diharapkan untuk terlibat secara aktif mereview terus-menerus.

\section{Analytic Reader}

Para pembaca yang termasuk dalam pola ini, menilai utilitarian value dari ulasan berdasarkan informasi yang tersedia tentang resensi dan peringkat terutama dari konsumen lainnya. pengaruh dan logika dari isinya.. Dalam hal ini, nilai ulasan terutama dinilai berdasarkan logika sangat dirasakan bermanfaat sebagai bahan pertimbangan. Oleh karena itu, nilai utilitarian yang dirasakan dari ulasan online dapat ditingkatkan dengan memberikan ulasan logis dan berpengaruh yang ditulis oleh pengulas aktif secara terus-menerus.

3 Synthetic Reader

Pembaca yang termasuk dalam pola ini menilai utilitarian value dari ulasan berdasarkan informasi yang tersedia tentang ulasan dan reputasi yang melakukan ulasan tersebut. Pembaca jenis ini akan menilai tulisan berdasarkan keaktifan pengulas, kecukupan ulasan, penyertaan foto dalam ulasan, peringkat ulasan, logika dan pengaruh isinya, dan perasaan mereka tentang ulasan tersebut. Oleh karena itu, nilai utilitarian ulasan online dapat ditingkatkan dengan memberikan ulasan logis dan berpengaruh yang mencakup foto, ditulis dalam nada positif, dan disusun oleh pengulas aktif secara terus-menerus.

4 Collaborative Reader

Pembaca ini mempertimbangkan semua elemen yang dipertimbangkan oleh "Analytic Reader" terutama nada emosional dan keaslian ulasan. Mereka juga mempertimbangkan informasi obyektif tentang pengulas. Tak hanya aspek cognitive, para pembaca jenis ini juga akan mempertimbangkan perasaan empatik yang diilhami oleh nada emosional atau ketulusan suatu ulasan. Dengan demikian, nilai utilitarian 
dari ulasan online dapat ditingkatkan dengan memberikan ulasan empatik yang ditulis oleh pengulas aktif secara terus-menerus.

\section{Image Appeal}

Secara umum, image appeal mengacu pada sejauh mana gambar pada situs web dan media sosial dianggap sesuai dan selaras dengan harapan pengguna media sosial (Cyr et al., 2006). Dalam lingkungan social commerce, image appeal tidak hanya dikaitkan dengan gambar dari suatu produk, tetapi juga gambar atau foto dari pengalaman orang lain yang telah menggunakan produk (Cyr et al., 2006).Lee dan Hong (2016) menunjukkan bahwa penelitian sebelumnya melihat informativeness sebagai satu-satunya karakteristik web yang sesuai iklan, peneliti juga melihat faktor-faktor lainnya seperti visual elements yang dapat meningkatkan nilai promosi pemasaran. Jika dibandingkan dengan informational elements, visual elements mampu meberikan dampak yang lebih besar pada sikap positif pengguna media sosial terhadap attitudes toward technology (Lee \& Chen, 2011). Visual elements miliki respons yang lebih mudah untuk menarik perhatian pengguna media sosial (Kim et al., 2007), untuk memperoleh daya tarik emosional kepada pengguna media sosial (Lowry, Romano, Jenkins, \& Guthrie, 2009) dan meningkatkan pengalaman positif pengguna media sosial dari segi teknologi (Choi, 2013).

Dalam konteks social commerce, desain gambar dari sebuah informasi pemasaran sebaiknya dapat mencakup elemen grafis, emosional dan estetika (Wang et al., 2019). Berbagai desian foto, pewarnaan, bentuk, dan font tulisan dapat memberikan efek yang sangat kuat dalam memberikan pemahanman dan presepsi positif kepada pengguna media sosial dalam promosi pemasaran produk atau jasa yang ditawarkan (Wang et al., 2019). Pertama, dibandingkan dengan pesan teks, pembentukan dengan image desain yang menarik membutuhkan sedikit upaya kognitif untuk menyampaikan informasi melalui foto, dengan demikian pengguna media sosial mampu memahami dan mengerti dengan baik informasi yang diberikan oleh pemasar. Seperti, visual gambar yang menunjukkan tekstur dan pewarnaan makanan yang menggugah selera pada produk Rendang Gadih, dengan visual gambar yang baik akan lebih efektif untuk membujuk para konsumen produk yang menggunakan media sosial dalam mencari informasi produk. Kedua, beberapa visual elements mampu meberikan respons yang lebih cepat kepada informasi pemasaran yang diberikan (Wang et al, 2019). Contohnya pengguna memberikan respon dengan memberikan "like" atau emogi pada foto yang diposting di akun media sosial, selian itu memberikan judul yang menarik pada foto mampu menarik perhatian konsumen untuk melihat foto yang diposting. Semakin jelas retorika visual (warna, bentuk, gambar) dari informasi pemasaran di media sosial, semakin besar kemungkinan pengguna media sosial akan memahami pesan yang disampaikan oleh pemasar.

\section{METODOLOGI PENELITIAN}

Penelitian ini melihat respon konsumen terhadap konten yang ada di media sosial Rendang Gadih Payakumbuh. Penelitian ini melihat puluhan ribu respon dari konsumen yang merupakan Follower dar Instagram Rendang Gadih untuk mengetahui Gambar dengan respon terbanyak. Penelitian ini memfokuskan pada meninjau gambar dan video yang terkait dengan konsep image appeal. Selanjutnya, secara kuantitatif, dilakukan survey pada 
100 orang Follower Rendang Gadih dipilih yang pernah setidaknya pernah melihat iklan media sosial berupa foto maupun video pada Instagram UKM Rendang Gadih. Tujuan penelitian ini adalah untuk melihat penilaian konsumen terkait iklan yang muncul di media sosial UKM Rendang Gadih sepanjang tahun 2019. Penelitian ini mengacu pada penelitian terdahulu yang dilakukan oleh studi dari Wang et al (2019) yang menilai Image Appeal dengan menggunakan sembilan indikator sebagai berikut:

1. Gambar pada iklan mempengaruhi secara emosional.

2. Gambar sesuai dengan norma.

3. Gambar dinilai menarik.

4. Gambar konsumen yang mengkonsumsi produk tersedia.

5. Gambar produk dalam iklan

6. Gambar pada iklan membuat konsumen tertarik.

7. Gambar pada iklan membuat konsumen bersemangat.

8. Gambar pada iklan menarik konsumen.

9. Gambar pada iklan mengundang selera.

Skala penilaian menggunakan Skala Likert 1-5 dimana 1 menunjukkan Sangat Tidak Setuju dan 5 untuk menggambarkan sikap Sangat Setuju terhadap setiap pernyataan yang diberikan. Hasil survey pada Follower UKM Rendang Gadih Payakumbuh ini kemudian diolah dengan menggunakan software SPSS untuk mengetahui rata rata respon konsumen terhadap Image Appeal Instagram Rendang Gadih dengan berdasarkan pada indikator oleh Wang (2019) tersebut.

\section{HASIL DAN PEMBAHASAN}

Kajian Respon Konsumen pada Konten Instagram UKM Rendang Gadih meliputi dua tahap. Pada tahapan pertama, kajian dilakukan dengan memperhatikan analisa konten dari media sosial Instagram Rendang Gadih sebagai salah satu perwakilan UKM yang telah menerapkan prinsipprinsip social commerce dalam media sosialnya. Sebagaimana terlihat pada Tabel 1, Iklan UKM Rendang Gadih ternyata telah dapat membuat followernya terlibat secara aktif dalam memberikan berbagai respon baik berupa meng-klik tayangan, memberikan respon suka atau like sampai pada memberikan komentar dan membagikan postingan yang dianggap bermanfaat pada sepanjang tahun 2019.

Tabel 1. Iklan UKM Rendang Gadih di Instagram dengan Respons Terbanyak tahun 2019

\begin{tabular}{|c|l|l|c|c|}
\hline No & $\begin{array}{c}\text { Tayang } \\
\text { untuk iklan } \\
\text { video }\end{array}$ & \multicolumn{1}{|c|}{ Jenis Konten } & $\begin{array}{c}\text { Jumlah } \\
\text { suka } \\
\text { (Like) }\end{array}$ & $\begin{array}{c}\text { Jumlah } \\
\text { Komentar }\end{array}$ \\
\hline 1 & 98.271 kali & $\begin{array}{l}\text { Video produk yang dipromosikan oleh } \\
\text { artis dan presenter Irfan Hakim. }\end{array}$ & 2.439 & 50 \\
\hline 2 & 57.157 kali & $\begin{array}{l}\text { Video review makanan foodvlogger } \\
\text { dari @yusifadila96 }\end{array}$ & 909 & 25 \\
\hline 3 & 55.982 kali & $\begin{array}{l}\text { Video berita dari PadangTV } \\
\text { Video review dari konsumen yang } \\
\text { menerangkan varian dan rasa produk }\end{array}$ & 432 & 14 \\
\hline 4 & 15.233 kali & $\begin{array}{l}\text { Video review makanan foodvlogger } \\
\text { dari @agakenyang }\end{array}$ & 238 & 22 \\
\hline 6 & 11.586 kali & $\begin{array}{l}\text { Video review makanan foodvlogger } \\
\text { dari @henjiwong }\end{array}$ & 206 & 12 \\
\hline
\end{tabular}

Jurnal Pemasaran Kompetitif, Vol. 03, No. 3 Juni 2020 
ISSN NO. (PRINI) 2598-0823, (ONLINE) 2598-2893

\begin{tabular}{|c|l|l|c|c|}
\hline 7 & 7.475 kali & $\begin{array}{l}\text { Video dari rivew konsumen yang } \\
\text { sedang mengkonsumsi produk }\end{array}$ & 587 & 47 \\
\hline 8 & 7.204 kali & $\begin{array}{l}\text { Video review makanan foodvlogger } \\
\text { dari @chitraria }\end{array}$ & 241 & 6 \\
\hline 9 & 8,180 kali & $\begin{array}{l}\text { Video review makanan foodvlogger } \\
\text { dari @nanakoot_ }\end{array}$ & 481 & 13 \\
\hline 10 & 6.362 kali & $\begin{array}{l}\text { Video review makanan foodvlogger } \\
\text { dari @eatandcouple }\end{array}$ & 817 & 39 \\
\hline
\end{tabular}

Sumber: Instagram official Rendang Gadih (2019)

Berdasarkan tabel 1 konten iklan video Rendang Gadih yang dipromosikan oleh presenter Irfan Hakim merupakan iklan yang memiliki respon konsumen paling tinggi. Konten iklan video tersebut memiliki jumlah like sebanyak 2.439, dan jumah komentar sebanyak 50 respon. Ternyata cukup banyak pula follower yang menyaksikan tayangan video yang dibuktikan dengan telah diputarnya sebanyak 126.598 kali tayang video iklan ini sebagaiman yang juga terlihat pada Gambar 2.

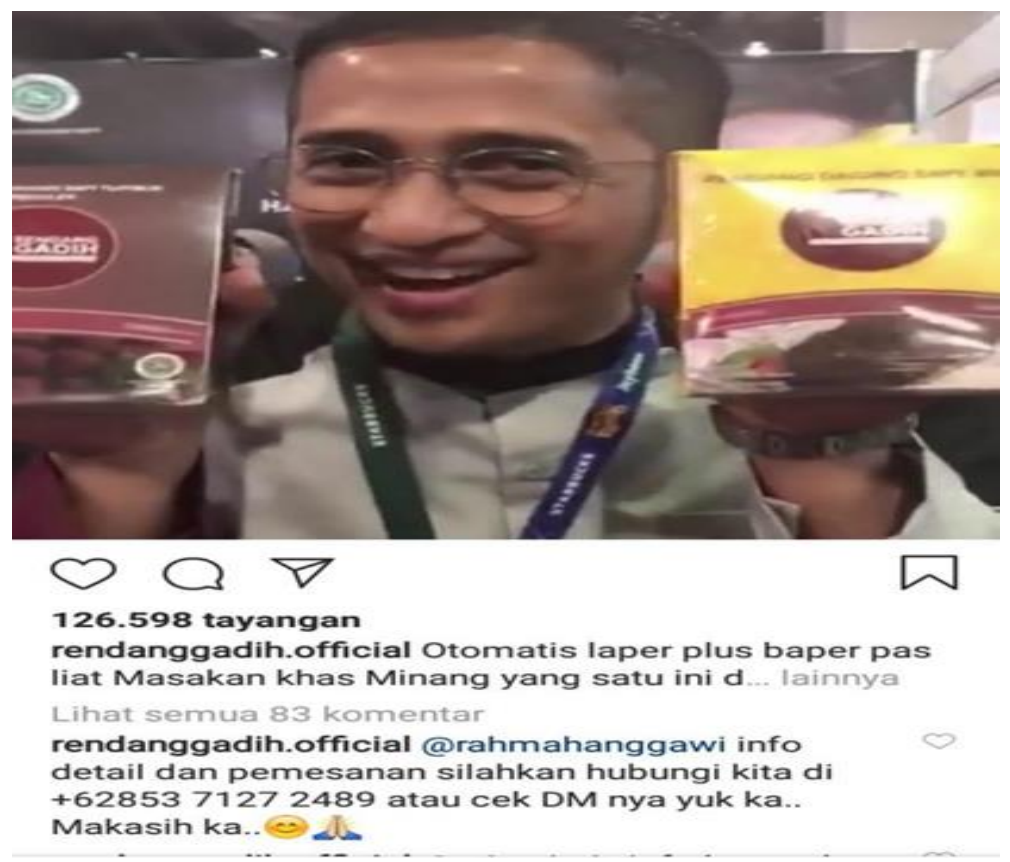

\section{Sumber: Instagram Rendang Gadih Payakumbuh}

Gambar 2. Video Iklan pada Instagram Rendang Gadih Payakumbuh

Sebagaimana uraian Tabel 1, pada postingan lainnya Rendang Gadih juga menampilkan respons dari foodvloger @yusifadila96 yang menggunakan hijab dengan respons konsumen terhadap like 909 kali dan 25 komentar, selain dengan menampilkan review dari foodvloger yang menggunakan hijab, Rendang Gadih juga menampilkan review dari konsumen chinese yaitu @nanakoot_yang lebih mampu menarik konsumen nonmuslim. Respon konsumen terhadap review yang diberikan foodvloger tersebut mampu menarik perhatian konsumen dengan memberi respons terhadap postingan Rendang 
Gadih tersebut. Dengan demikian pemasaran melalui media sosial bisa menjadi lebih efektif dengan menggunakan video dan foto dari foodvloger, influencer, dan review kosumen, sehingga kepercayaan konsumen terhadap kualitas produk akan menjadi sangat baik dibantu dengan pemasaran media sosial atau social commerce.

Tabel 2. Pendapat Responden Tentang Image Appeal pada Instagram Rendang Gadih

\begin{tabular}{|c|c|c|c|c|c|c|c|c|}
\hline \multirow[b]{2}{*}{ No } & \multirow{2}{*}{ Pernyataan } & \multicolumn{5}{|c|}{ Frekuensi } & \multirow{2}{*}{ Jumlah } & \multirow[t]{2}{*}{ Rata-rata } \\
\hline & & STS & TS & $\mathbf{N}$ & $\mathrm{S}$ & SS & & \\
\hline 1. & $\begin{array}{l}\text { Gambar yang digunakan dalam } \\
\text { iklan Instagram Rendang } \\
\text { Gadih mempengaruhi saya } \\
\text { secara emosional. }\end{array}$ & 0 & 5 & 17 & 37 & 41 & 100 & $\begin{array}{c}4,14 \\
\text { Terendah }\end{array}$ \\
\hline 2. & $\begin{array}{l}\text { Gambar yang digunakan dalam } \\
\text { iklan di Instagram Rendang } \\
\text { Gadih sesuai dengan norma } \\
\text { yang ada di Indonesia. }\end{array}$ & 0 & 0 & 6 & 42 & 52 & 100 & 4,46 \\
\hline 3. & $\begin{array}{l}\text { Gambar yang digunakan dalam } \\
\text { iklan di Instagram Rendang } \\
\text { Gadih sangat menarik. }\end{array}$ & 0 & 1 & 9 & 36 & 54 & 100 & 4,43 \\
\hline 4. & $\begin{array}{l}\text { Saya suka melihat video } \\
\text { konsumen yang mengkonsumsi } \\
\text { produk. }\end{array}$ & 0 & 0 & 13 & 40 & 47 & 100 & 4,34 \\
\hline 5. & $\begin{array}{l}\text { Saya suka melihat gambar } \\
\text { konsumen yang mengkonsumsi } \\
\text { produk. }\end{array}$ & 0 & 1 & 14 & 45 & 40 & 100 & 4,24 \\
\hline 6. & $\begin{array}{l}\text { Saya suka melihat tampilan } \\
\text { gambar produk pada iklan di } \\
\text { Instagram Rendang Gadih. }\end{array}$ & 0 & 2 & 12 & 41 & 45 & 100 & 4,29 \\
\hline 7. & $\begin{array}{l}\text { Saya suka menonton video } \\
\text { produk pada iklan di Instagram } \\
\text { Rendang Gadih. }\end{array}$ & 0 & 2 & 18 & 32 & 48 & 100 & 4,26 \\
\hline 8. & $\begin{array}{l}\text { Gambar pada iklan Instagram } \\
\text { Rendang Gadih membuat saya } \\
\text { tertarik. }\end{array}$ & 0 & 0 & 11 & 44 & 45 & 100 & 4,34 \\
\hline 9. & $\begin{array}{l}\text { Gambar yang digunakan dalam } \\
\text { iklan di Instagram Rendang } \\
\text { Gadih membuat saya } \\
\text { bersemangat. }\end{array}$ & 0 & 0 & 20 & 37 & 43 & 100 & 4,23 \\
\hline 10. & $\begin{array}{l}\text { Gambar yang digunakan iklan di } \\
\text { Instagram Rendang Gadih } \\
\text { menarik bagi saya. }\end{array}$ & 0 & 0 & 11 & 45 & 44 & 100 & 4,33 \\
\hline 11. & $\begin{array}{l}\text { Iklan produk Rendang Gadih di } \\
\text { Instagram Rendang Gadih } \\
\text { terlihat mengundang selera. }\end{array}$ & 0 & 0 & 9 & 34 & 57 & 100 & $\begin{array}{c}4,48 \\
\text { Tertinggi }\end{array}$ \\
\hline \multicolumn{8}{|c|}{ Total } & 47,54 \\
\hline \multicolumn{8}{|c|}{ Nilai Rata-Rata Pendapat Responden Tentang Image Appeal } & 4,322 \\
\hline
\end{tabular}

Sumber : Pengolahan Data Primer (2019) 
Berdasarkan Tabel 2 di atas terlihat bahwa penilaian tertinggi terhadap pernyataan pada variabel image appeal terdapat pada pernyataan Nomor 11 yaitu, "Iklan produk Rendang Gadih di Instagram Rendang Gadih terlihat mengundang selera" dengan nilai rata-rata sebesar 4,48. Sedangkan penilaian terendah terhadap pernyataan pada pernyataan Nomor 1, yaitu "Gambar yang digunakan dalam iklan Instagram Rendang Gadih mempengaruhi saya secara emosional " dengan nilai rata-rata sebesar 4,1. Secara umum terlihat bahwa gambar dan video yang ditampilkan pada iklan Rendang Gadih di media sosial Instagram sudah sangat sangat menarik walaupun dari aspek emosional hal ini memiliki skor yang lebih rendah digabandingkan pernyataan lainnya. Secara umum, nilai rata-rata responden tentang image appeal pada Instagram Rendang Gadih adalah sebesar 4,3 yang mana hasil tersebut menunjukkan bahwa pendapat para responden secara keseluruhan terhadap image appeal bisa dikatakan baik, artinya konsumen merasa image appeal pada iklan di Instagram UKM Rendang Gadih sudah memuaskan.

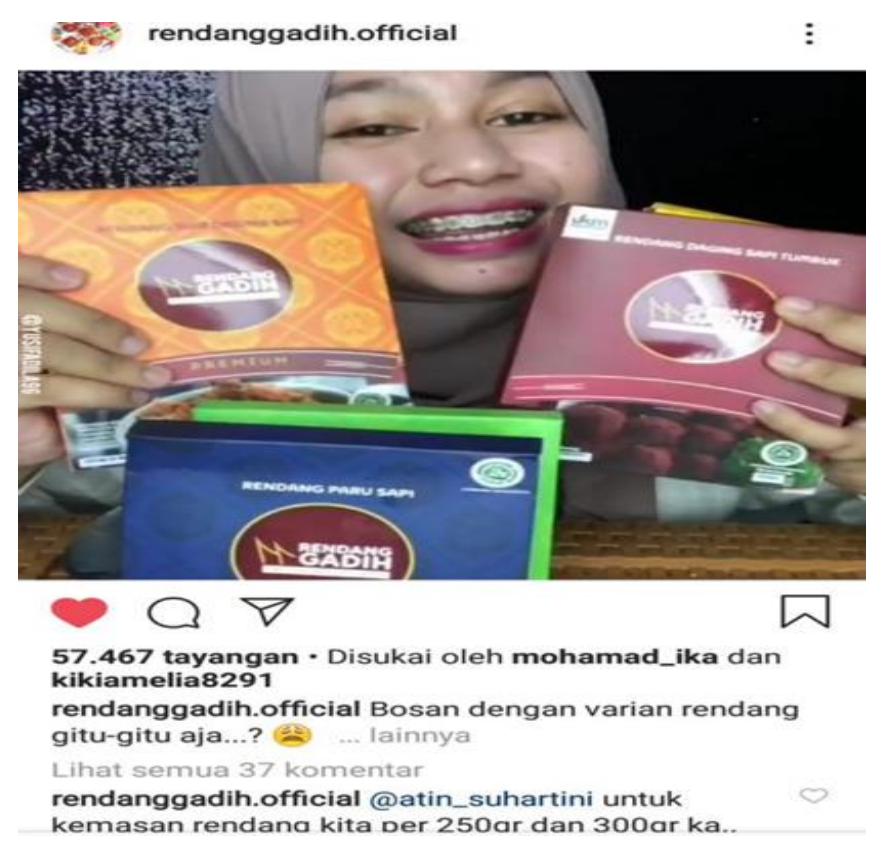

Sumber: Instagram Rendang Gadih Payakumbuh

Gambar 3. Tampilan kemasan Produk

Dalam skala 1-5, konsumen memberikan penilaian rata rata sebesar 4,29 dalam arti rata rata memilih setuju dan bahkan sangat setuju tentang munculnya gambar kemasan produk pada media sosial Instagram Rendang Gadih. Kemasan produk ini ternyata relah direspon positif oleh konsumen karena kemasan telah meningkatkan familiaritas konsumen terhadap tampilan produk. Hal lainnya yang menarik adalah penggunaan selegram dan vlogger yang berasal dari etnik yang beragam dalam Rendang Gadih ini yang cukup berbeda dari UKM sejenis dari Sumatera Barat. Pada Gambar 3 terlihat gadis dengan hijab, sementara pada Gambar 4 terlihat Gadis muda lainnya dengan perbedaan penampilan. Ini dapat berarti bahwa Rendang Gadih dapat diterima oleh beragam lidah dan selera konsumen di Indonesia. Dapat dilihat bahwa konsumen menilai hal tersebut sangat baik dengan memberikan penilaian sebesar 4,46 bahwa Rendang Gadih telah menampilkan gambar yang sesuai dengan norma yang berlaku di Indonesia. 


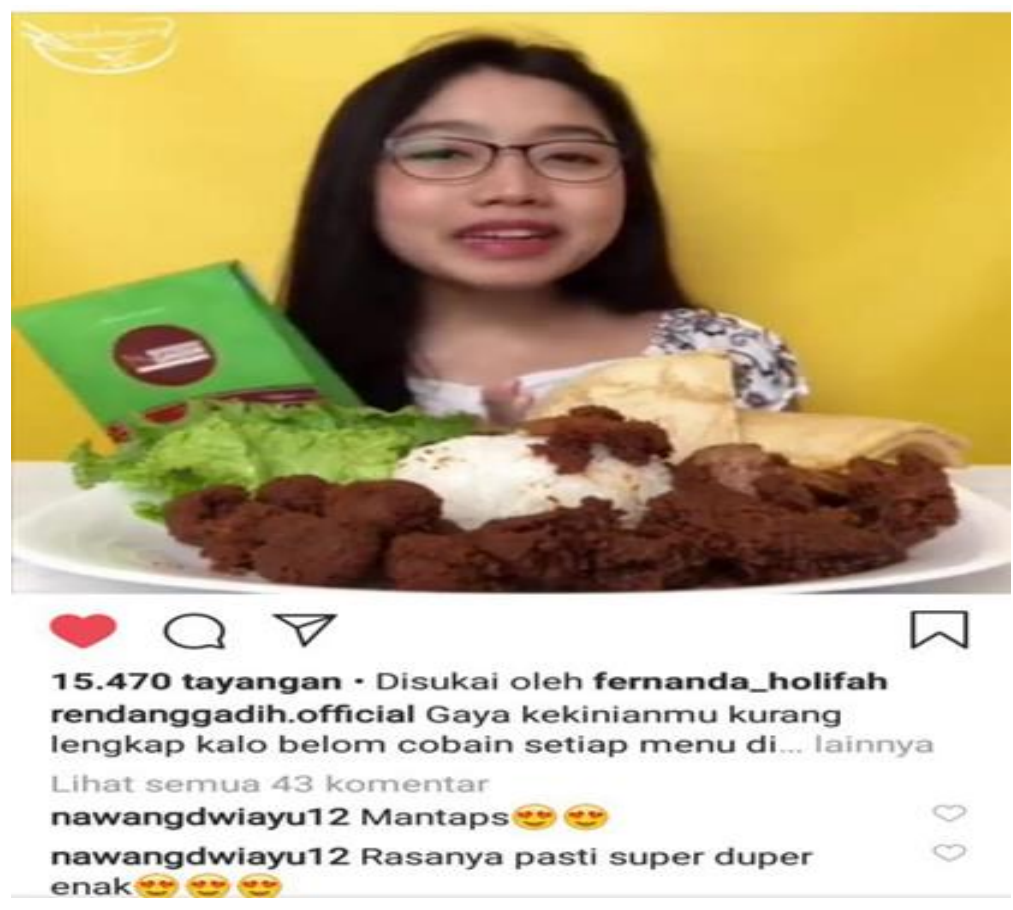

Sumber: Instagram Rendang Gadih Payakumbuh

\section{Gambar 4 . Tayangan Video Food Vlogger Mengkonsumsi Produk}

Sebagaimana terlihat pada Tabel 2, konsumen ternyata sangat menilai baik tampilan dari Food Vlogger yang menampilkan video dengan cara langsung mengkonsumsi produk. Bagi konsumen, ini adalah nilai terbaik dari pada iklan iklan video lainnya. Dengan adanya video tampilan cara mengkonsumsi produk (Gambar 4), konsumen menjadi sangat tertatrik dengan video tersebut dan seolah membayangkan mereka berada pada posisi serupa. Temuan studi ini sejalan dengan penelitian terdahulu oleh $\mathrm{Ham}$ et al (2019) dimana pembaca biasanya sangat mengapresiasi ketulusan dan kejelasan sebuah postingan pada media sosial. Makin bergambar sebah iklan, makin menarik minat terutama jika endorser yang digunakan adalah juga mereka yang telah dikenal baik oleh para konsumen. Ketika makin banyak konsumen ikut berinteraksi, akan membuat sebuah iklan makin dipercaya oleh konsumen lainnya. Wang et al (2019) juga telah membuktikan bahwa adanya sebuah postingan yang menarik akan merangsang konsumen untuk ikut membagikan postingan tersebut pada media sosial.

\section{E. KESIMPULAN}

UKM harus dapat mengerti kebutuhan konsumen, termasuk tentang penilaian konsumen terhadap iklan di media sosial. Pada Instagram Rendang Gadih Payakumbuh, penilaian tertinggi terletak pada kemampuan akun Instagram ini menampilkan produk sajian rendang yang mengundang selera yang diperlihatkan oleh Food Vlogger. Video dengan tayangan terbanyak adalah video dengan menampilkan Irfan Hakim yang merupakan salah satu artis ternama Indonesia. Iklan yang baik dan menarik dapat mempertimbangkan penggunaan gambar dan video yang menarik yang lazim dikenal dengan Image Appeal. Pilihan gambar dan video yang tepat akan membuat konsumen tidak bosan terhadap tampilan sebuah akun media sosial. Dengan Image Appeal yang tepat, konsumen akan merasa ingin terlibat dalam interaksi pada media sosial. Gambar dan video yang menampilkan kemasan produk serta gambaran nyata produk termasuk 
bagaimana mengkonsumsi produk tersebut adalah yang paling membuat konsumen tertarik pada sebuah iklan Instagram. Makin bervariasi dan kreatif image appeal yang ditampilkan dalam media sosial akan dapat menarik minat konsumen untuk memberikan penilaian positif pada suatu iklan.

\section{DAFTAR PUSTAKA}

Arianto, N \& Giovanni. (2020). Pengaruh Kualitas Produk dan Harga terhadap Keputusan Pembelian, Jurnal Pemasaran Kompetitif, 3(2), 12-20.

Choi, N. (2013). Letter to the Editor: Answer to Professor Szostak (concept theory). Journal of the American Society for Information Science \& Technology, 61(5), 1078-1079. https://doi.org/10.1002/asi

Cyr, D., Head, M., Larios, H., \& Pan, B. (2006). Exploring Human Images in Website Design Across Cultures: A Multi-Method Approach. SIGHCI 2006 Proceedings, 33(3), 539-566. Retrieved from http://aisel.aisnet.org/sighci2006/6

Datareportal.com. (2019). Digital 2019 Global Digital Overview, Available at: https://datareportal.com/reports/digital-2019-global-digital-overview [Assessed $1^{\text {st }}$ January 2020]

Dong, X., \& Wang, T. (2018). Social Tie Formation in Chinese Online Social Commerce: The Role of IT Affordances. International Journal of Information Management, 42(June), 49-64. https://doi.org/10.1016/j.jijnfomgt.2018.06.002

Gonçalves C, R., \& Zhang, P. (2013). Website Features That Gave Rise to Social Commerce: A historical analysis. Electronic Commerce Research and Applications, 12(4), 260-279. https://doi.org/10.1016/..elerap.2013.04.001

Ham, J., Lee, K., Kim, T., \& Koo, C. (2019). Subjective Perception Patterns of Online Reviews : A Comparison of Utilitarian and Hedonic Values. Information Processing and Management, 56(4), 1439-1456. https://doi.org/10.1016/j.ipm.2019.03.011

Han, H., Xu, H., \& Chen, H. (2018). Social Commerce: A Systematic Review and Data Synthesis. Electronic Commerce Research and Applications, 30(May), 38-50. https://doi.org/10.1016/..elerap.2018.05.005

Kesari, B., \& Atulkar, S. (2016). Satisfaction of Mall Shoppers: A Study on Perceived Utilitarian And Hedonic Shopping Values. Journal of Retailing and Consumer Services, 31, 22-31. https://doi.org/10.1016/j.jretconser.2016.03.005

Kim, H. W., Chan, H. C., \& Gupta, S. (2007). Value-Based Adoption of Mobile Internet: An Empirical Investigation. Decision Support Systems, 43(1), 111-126. https://doi.org/10.1016/j.dss.2005.05.009

Lee, J., \& Hong, I. B. (2016). Predicting Positive User Responses to Social Media Advertising: The Roles of Emotional Appeal, Informativeness, and Creativity. International Journal of Information Management, 36(3), 360-373. https://doi.org/10.1016/j.jinfomgt.2016.01.001 
Lee, Y., \& Chen, A. (2011). Usability Design and Psychological Ownership of A Virtual World. Journal of Management Information Systems, 28(3), 269-307. https://doi.org/10.2753/MIS0742-1222280308

Lesmana, R. (2017). Pengaruh Citra Perusahaan Terhadap Keputusan Pembelian Konsumen Pt. Garuda Indonesia Tbk.(Persero). JIMF (Jurnal IImiah Manajemen Forkamma), 1(1).

Lowry, P., Romano, N., Jenkins, J., \& Guthrie, R. (2009). The CMC Interactivity Model: How Interactivity Enhances Communication Quality and Process Satisfaction in Lean-Media Groups. Journal of Management Information Systems, 26(1), 155-195. https://doi.org/10.2753/MIS0742-1222260107

Nurmufida, M., Wangrimen, G. H., Reinalta, R., \& Leonardi, K. (2017). Rendang: The Treasure of Minangkabau. Journal of Ethnic Foods, 4(4), 232-235. https://doi.org/10.1016/j.jef.2017.10.005

Wang, W., Rui, R., Xiaojuan, C., \& Jifan, S. (2019). Computers in Human Behavior Media or Message , Which is The King in Social Commerce?: An Empirical Study of Participants ' Intention to Repost Marketing Messages on Social Media. Computers in Human Behavior, 93(March 2018), 176-191. https://doi.org/10.1016/j.chb.2018.12.007

Yadav, M. S., Valck, K. De, Hennig-thurau, T., Hoffman, D. L., \& Spann, M. (2013). ScienceDirect Social Commerce: A Contingency Framework for Assessing Marketing Potential. Journal of Interactive Marketing, 27(4), 311-323. https://doi.org/10.1016/j.intmar.2013.09.001

Zhang, K. Z. K., \& Benyoucef, M. (2016). Consumer behavior in Social Commerce: A literature review. Decision Support Systems, 86, 95-108. https://doi.org/10.1016/j.dss.2016.04.001 